\title{
Distant Labour Supply, Skills and Induced Technical Change
}

Ashima Goyal

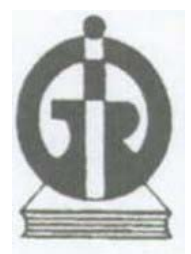

Indira Gandhi Institute of Development Research, Mumbai December 2006 


\title{
Distant Labour Supply, Skills and Induced Technical Change
}

\author{
Ashima Goyal \\ Indira Gandhi Institute of Development Research (IGIDR) \\ General Arun Kumar Vaidya Marg \\ Goregaon (E), Mumbai- 400065, INDIA \\ Email: ashima@igidr.ac.in
}

\begin{abstract}
To analyze the consequences of new technologies, which make it possible to employ distant labour, we model a developed country with high and medium-skilled labour interacting with an emerging market economy (EME) with medium and low-skilled labour. Expansion in labour supply induces medium-skill biased technical change, which raises the demand for such labour. As a result, inequalities tend to fall in the developed country, skill premiums rise marginally in the EME, but equality rises because labour employed in the low-skilled sector shrinks. Inequality falls across the countries since average wages, information and access rise in the EME.
\end{abstract}

Key words: Internet and communication technology; induced technological change; relative factor supplies; labour skills.

JEL Code(s): O31, O14, J61 


\section{Distant Labour Supply, Skills and Induced Technical Change}

\section{Introduction ${ }^{* *}$}

\section{Ashima Goyal}

New Internet and communication technologies (ICT) make global sourcing possible for a variety of activities. This expands the labour supply available to many developed country firms, and the employment opportunities for labour in emerging market economies (EMEs). This paper examines potential effects on induced technical change, on the transition to development of populous EMEs, and on equality within and across countries.

What effect does availability of a resource have on technical development? Technical change sometimes compensates for a scarce resource. But abundance of a resource can also stimulate technology to utilize it. For example, deforestation gave Britain an early lead in developing coal resources but deforestation in China did not have the same effect. Water mill technology developed in river rich North Europe but it did not in rainier New Guinea ${ }^{1}$. How will the large expansion in global labour supply, of a particular type, affect technical development?

Global sourcing provides jobs for labour with some basic skills. ICT increases the availability of this class of skills; there is evidence that differential availability of skills induces skill biases in technical change. These biases affect wage dispersion and equality. Habbakuk (1962) argued that the early nineteenth century increase in supply of unskilled labour to English cities led to the development of unskilled labour-biased or skill-replacing technologies such as the factory system that replaced skilled artisans. Adoption of the factory system in the US was delayed due to the absence of cheap labour supplies ${ }^{2}$.

\footnotetext{
** I thank two anonymous referees for very useful comments, and T.S. Ananthi for help with the word processing.

${ }^{1}$ These examples are from Diamond (1997).

${ }^{2}$ The English population more than doubled during this period while the share of agricultural labour force fell from about seventy percent to about twenty percent. The increase in the supply of unskilled labour to cities occurred due to enclosures and labour releasing technical change in rural areas, and a large migration from Ireland (Acemoglu, 2002).
} 
Since basic research and major technical inventions normally occur before they are really used, technology is exogenous in that sense. But its adoption and further adaptation responds to economic incentives ${ }^{3}$. Schmookler (1966) argued for the importance of demand-pull and the market size for the development of technology and gave many examples of these effects. A famous instance was the high rate of innovation in horseshoes that lasted only as long as horses were commonly used. In the endogenous growth literature also technology develops in response to market incentives (see, for example, Aghion and Howitt, 1992). The rise in the market size for techniques adapted to medium-skills may be expected to stimulate more of such adaptations.

Acemoglu (2002) argues that the sharp rise in wage inequality in the US from the 1980s was due to skill-biased technical change induced by expanding supply of skilled labour.

We adapt his framework to analyze the consequences of distance work, which implies a large increase in the supply of medium-skilled labour. In our model, when a developed country with high and medium-skilled labour interacts with an emerging market economy (EME) with medium and low-skilled labour, since medium-skills available rise, the market size effect induces medium-skill biased technical change, which raises the demand for such labour. As a result, inequalities tend to fall in the developed country, skill premiums rise marginally in the EME, but equality rises because labour employed in the low-skilled sector shrinks. Inequality falls across the countries since average wages, information and access rise in the EME. The transition to development can be more rapid.

The new global mobility of capital suggests that differential labour skills may be more critical for development than capital itself. During the catch-up process for latecomers like the US and East Asia, technical development was capital using, but ICT available to populous EMEs that are currently in the catch-up phase is labour-using, validating the focus on labour skills. Technology and its import play a major role in the

\footnotetext{
${ }^{3}$ Diamond (1997) emphasizes relative economic advantage compared with existing technology as a strong influence on acceptance of innovations. Other factors he lists as important are the social value and prestige attached to the new technology, the ease with which its advantages can be observed, and its compatibility with vested interests. ICT has advantages on all these grounds, except for the last point where some short-term losers create resistance.
} 
transition from a developing to a mature economy. Although a sustained rise in total factor productivity (TFP) occurs with modern economic growth, a different pattern is often observed in the initial stages of development, with a bias in technology towards using one factor (Hayami, 1998) ${ }^{4}$. Technology used in the Asian economies had a capital-using and labour-saving bias although labour was naturally more abundant suggesting labour-using technology should have been developed. Capital deepening was also inconsistent with Kuznet's pattern of modern economic growth during which capital-output ratios fell as TFP rose. Hayami suggests the difference arose partly because the Western technology imitated was capital intensive. He also finds a similar pattern for the US catch-up years of the early to mid-nineteenth century. The capitaloutput ratio rose and the contribution of TFP to growth in labour productivity was less than that of the growth in capital-labour ratio. The Kuznet's pattern emerged after 1890 when it had reached maturity. Growth accounting for the early period of Japanese industrialization also supports this picture. Technology adopted was heavily influenced by technology available from the developed countries, and for successful development capital resources had to be made available to suit the technology bias. But today it is possible that technology available will have a medium- rather than a high-skill or capital-bias.

The structure of the paper is as follows. After a brief look at the impact of ICT on labour availability, section 3 models the effect of technical change and relative labour skills on the labour market, considering first the developed and then the emerging market. A sub-section draws out the impact of endogenous technical change in each case. Section 4 analyzes the effect of global sourcing, before section 5 draws out some implication for policy and concludes.

\section{Why is more labour available on the global market?}

The short answer is new technologies that make global sourcing feasible. A few statistics indicate the changes taking place in the availability of labour, and the financial incentives for companies to source distant labour (Goyal, 2006). The

\footnotetext{
${ }^{4}$ Compared to developed economies, the growth rates of labour productivity in the four East Asian 'Tigers' were almost twice as high, but TFP growth rates were lower. TFP's contribution to labour productivity growth, in the Asian economies, therefore, was less than half its contribution in developed economies. Very high rates of growth in capital labour ratios and a high response of output to capital were responsible for these outcomes.
} 
percentage of US multinational companies outsourcing financial functions over 200204 was 77, compared to 72 percent of European companies. Moreover, 71 percent of European companies compared to 78 percent in the US planned to use these services over the next two years ${ }^{5}$. Global Insight (2004) estimated that 2 percent of ten million US computer related jobs had been sent abroad and 12 percent of IT companies had outsourced work. A high-end projection from Forrester Research was that 3.3 million US jobs would go abroad by 2015, including 1.7 million back-office jobs, or 200,000 jobs annually for the decade starting in 2005 . But this is still only a small dent in the American labour market.

There are major cost advantages. McKinsey Global Institute (2003) estimates that one dollar of US job loss creates from 1.45 to 1.47 dollars of global value added out of which the US gets back 1.12 to 1.14 dollars through various channels, including higher exports, while the country receiving the offshoring job gets just 33 cents. Dossani and Kenney (2003) write that outsourcing to India saved GE \$340 million annually. These statistics make it clear why there is strong labour demand for the range of jobs that can be outsourced, to make use of labour supply available.

A large population size induces more technical change because of the market size effect. It helps in other ways also: more people are trained, there are more potential inventors, more competing groups, more innovations to adopt, more pressures to innovate. We focus on the market size effect in the section below.

\section{Modelling the effects of technical change and relative labour skills on market outcomes}

The essence of global sourcing is that it allows labour from one country to be used in the production processes of another country. Normally it is a firm based in a developed country that uses cheaper EME labour in this way. We develop a simple analytical framework to focus on the consequences of the expansion in labour supply on the nature of technical change, on the catch-up path of populous EMEs, on wage differentials and on equality.

\footnotetext{
${ }^{5}$ PricewaterhouseCoopers' Management Barometer Survey, reported in the Economic Times, Internet Edition, October 31, 2004.
} 
There are three types of workers high $(H)$, medium $(M)$ and low $(L)$ skilled. High skills come from a professional degree or training, medium-skill workers have an undergraduate or school degree, while low-skill workers include barely literate categories, with a few years of schooling or informal training. Workers in the developed country $(d)$ are largely of type $\mathrm{H}$ and $\mathrm{M}$, and in the emerging economy $(e)$ of type $\mathrm{M}$ and $\mathrm{L}$. These are simplifying assumptions: the developed country will have some illiterate workers while the EME will have highly skilled ones. But the assumptions make it possible to obtain analytical results capturing dominant tendencies. Although workers in the EME may have a professional degree the low quality of the degree can make them effectively of type M. We model ICT as creating a comparative static shock to the amount of M-skills available in the global market.

\subsection{The developed country}

Since the aggregate output in each economy is produced by a combination of two types of workers we can write the aggregate production function for the developed economy in the constant elasticity of substitution (CES) form, where $\rho \leq 1$, and the A terms represent factor - augmenting technology.

$$
Y_{d}(t)=\left[\left(A_{m}(t) M_{d}(t)\right)^{\rho}+\left(A_{h}(t) H(t)\right)^{\rho}\right]^{1 / \rho}
$$

Labour markets are competitive; all workers are risk neutral and maximize the discounted present value of labour income. The $\mathrm{M}_{\mathrm{d}}(\mathrm{t})$ medium-skilled and $\mathrm{H}(\mathrm{t})$ highskilled workers are imperfect substitutes in producing the output of the economy. The elasticity of substitution between the two types of workers in this production function is $\sigma \equiv 1 /(1-\rho)$. Empirical estimates ${ }^{6}$ of $\sigma$ suggest that $\sigma>1$ (or $\rho>0$ ) so that the two worker types are gross substitutes. In this case a rise in $A_{m}$ relative to $A_{h}$ will be medium skilled-biased or skill-replacing. A rise in $\mathrm{A}_{\mathrm{m}}$ will "complement" mediumskilled workers, increasing demand for such workers ${ }^{7}$. We will derive this more formally below.

\footnotetext{
${ }^{6}$ Freeman (1986) surveys a large number of estimates for the elasticity of substitution between more and less educated labour, and concludes the evidence suggests a range between 1 and 2 (pp. 366).

${ }^{7}$ If $\sigma<1$ (or $\left.\rho<0\right)$ an increase in $A_{m}$ will create an "excess supply" of medium-skilled workers, given the number of such workers available. It will therefore complement or raise the demand for skilled workers and will replace medium-skilled workers.
} 
The aggregate production function (1) can be interpreted as either holding for a one good economy, or for a multi-good economy where different sectors employ both $\mathrm{M}$ and $\mathrm{H}$ workers and produce goods that are imperfect substitutes, or for a two-good economy, each produced by one type of worker and aggregated by consumer preferences over the two goods. The last interpretation is used since it is the simplest. Time subscripts are also dropped to save notation.

Considering first labour demand and supply in a closed economy. Labour of each skill type is inelastically supplied. The production functions for the two goods in economy $d$ are:

$$
\begin{aligned}
& Y_{\mathrm{h}}=A_{\mathrm{h}} \mathrm{H} \\
& \mathrm{Y}_{\mathrm{md}}=\mathrm{A}_{\mathrm{md}} \mathrm{M}_{\mathrm{d}}
\end{aligned}
$$

The consumers' utility function, defined over the two goods, is:

$$
\left[Y_{m d}^{\rho}+Y_{h}^{\rho}\right]^{1 / \rho}
$$

Since labour markets are competitive, the wage for each skill class of labour equals its marginal product.

$$
\begin{aligned}
& w_{M d}=\frac{\delta Y_{d}}{\delta M_{d}}=A_{m d}^{\rho}\left[A_{m d}^{\rho}+A_{h}^{\rho}\left(H / M_{d}\right)^{\rho}\right]^{(1-\rho) / \rho} \\
& w_{H}=\frac{\delta Y_{d}}{\delta H}=A_{h}^{\rho}\left[A_{m d}^{\rho}\left(H / M_{d}\right)^{-\rho}+A_{h}^{\rho}\right]^{(1-\rho) / \rho}
\end{aligned}
$$

The two equations imply that $\delta w_{M d} / \delta\left(M_{d} \mid H\right)<0$ and $\delta w_{H} / \delta\left(M_{d} \mid H\right)>0$.

Everything else equal, as medium-skilled workers become more abundant relative to skilled, their wages should fall and the skilled-worker wage should rise.

The skill premium, or the wage of skilled workers divided by the wage of mediumskilled workers, is obtained by combining equations (4):

$$
\omega_{d}=\frac{w_{H}}{w_{M d}}=\left(\frac{A_{h}}{A_{m d}}\right)^{\rho}\left(\frac{H}{M_{d}}\right)^{-(1-\rho)}=\left(\frac{A_{h}}{A_{m d}}\right)^{(\sigma-1) / \sigma}\left(\frac{H}{M_{d}}\right)^{-1 / \sigma}
$$

Or, taking logs,

$$
\ln \omega_{d}=\frac{\sigma-1}{\sigma} \ln \left(\frac{A_{h}}{A_{m d}}\right)-\frac{1}{\sigma} \ln \left(\frac{H}{M_{d}}\right)
$$

Differentiating (4), 


$$
\frac{\delta \ln \omega_{d}}{\delta \ln \left(H / M_{d}\right)}=-\frac{1}{\sigma}<0
$$

The skill premium increases as skilled workers become relatively scarce, for a given skill bias of technology. Equation (6) gives the relative demand curve for skills, and equation (7) its slope in $\omega_{d}$ and $H / M_{d}$ space (Figure 1). The demand curve is downward sloping with elasticity $1 / \sigma=(1-\rho)$. The slope captures the substitution effect arising from a substitution of medium-skilled workers for skilled workers in tasks the latter were doing, and from a substitution in consumption of the medium skilled good for the skilled good, as skilled workers become relatively scarce.

Figure 1 graphs the relative demand for skills equation (6). Given relative supply $\mathrm{H} / \mathrm{M}_{\mathrm{d}}$ the equilibrium relative wage or skill premium is $\omega_{\mathrm{d}}$. If, with global sourcing, $\mathrm{M}_{\mathrm{d}}$ rises to $M_{d}^{\prime}$, the relative supply curve shifts inwards and the comparative static result has skill premium rising along the downward sloping demand curve to $\omega_{d}^{\prime}$.

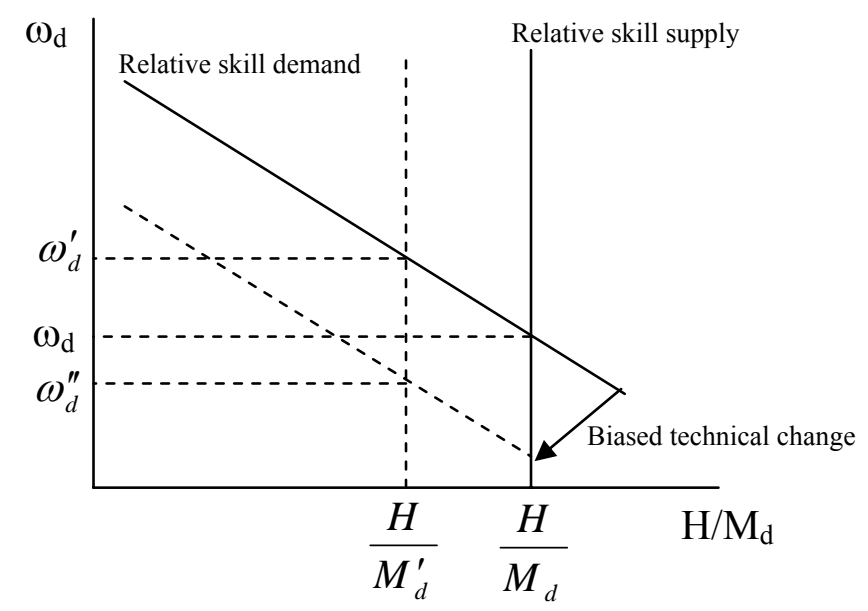

Figure 1: The relative demand for skills and relative wages in the developed country

But that demand curve takes technology as given. Differentiating equation (6) with respect to $\left(A_{h} / A_{m d}\right)$ shows:

$$
\frac{\delta \ln \omega_{d}}{\delta \ln \left(A_{h} \mid A_{m d}\right)}=\frac{\sigma-1}{\sigma}>0 \quad \text { if } \quad \sigma>1
$$

If $\mathrm{A}_{\mathrm{md}}$ rises with the increased availability of medium-skilled workers the relative demand for high skills will shift inwards and the final skill premium will be $\omega_{d}^{\prime \prime}<\omega_{d}^{\prime}$. 
That is the high-skill premium will fall, and under certain conditions (we explore below) may even be lower than the initial.

For example, despite a large influx of skilled workers from the former Soviet Union into Israel in the early nineties, the education premium did not fall, perhaps because of the above type of shift in demand in response to a change in supply of a factor. (Acemoglu, 2002).

But how does a rise in $M_{d}$ affect $\mathrm{A}_{\mathrm{md}}$ ? We examine this question in the next section.

\subsubsection{Endogenous technical change}

Acemoglu (2002 pp. 31-38) gives many historical examples where technology or organization of production has responded to profit opportunities determined partly by the market size for the technology. He explains the sharp rise in skill premiums in the US after the 1970s, despite a large rise in the supply of skills, as due to skill-bias in technological development, driven by the expanding market size for such technology. He distinguishes between "macroinventions" or advances in basic science that are independent of profit motives, and the "microinventions" or applications that follow. In our context, given the availability of basic ICT technologies, firms face a choice between installing an ICT machine that can be used by a skilled or a medium-skilled worker, or developing a process that raises the productivity of one or the other worker. If profit motives affect this choice and therefore advances in applications, endogenous skill bias results. An increase in the relative size of one skilled set can make it profitable to produce more applications for that set. Schmookler (1966) and the endogenous growth school has more recently developed the theme of the response of technology to profit incentives.

The sectoral production functions can be written as $Y_{h}=N_{h} H$ and $Y_{m d}=N_{m d} M_{d}$ where $\mathrm{N}_{\mathrm{h}}$ and $\mathrm{N}_{\mathrm{md}}$ are the number of specialized machines for skilled and mediumskilled workers respectively. $A_{h}=N_{h}$ and $A_{m d}=N_{m d}$ so that the production functions are equivalent to those in the above section ${ }^{8}$. Consumers' maximize utility (3), subject

\footnotetext{
${ }^{8}$ Here we present a simple version with a linear technology, since that is sufficient for our initial comparison between a developed country and an EME. But Acemoglu (1998) derives such a linear aggregate technology from a more complex model with a continuum of firms and machines. Each firm
} 
to a budget constraint, leading to a standard relative demand function for the two goods, under competitive conditions. Substituting the production functions in the inverted demand function, the relative price of the skill intensive good can be written:

$$
p_{d}=\frac{p_{h}}{p_{m d}}=\left[\frac{N_{h} H}{N_{m d} M_{d}}\right]^{\rho-1}
$$

Assume creating a new machine has a fixed $\operatorname{cost} C$ in units of final output $Y$, but the marginal cost of producing a machine is zero once it is created. The marginal willingness to pay for the creation of new machines is given by the marginal increase in profit due to new machine. This, in each sector, is given by the derivative of $p_{h} Y_{h}$ and $p_{m d} Y_{m d}$ with respect to $N_{h}$ and $N_{m d}$, that is

$$
\mathrm{p}_{\mathrm{h}} \mathrm{H} \text { and } \mathrm{p}_{\mathrm{md}} \mathrm{M}_{\mathrm{d}}
$$

The creation of new machines stops when this marginal increase in profit equals the marginal cost of innovation in both sectors. Therefore, in equilibrium, it must be that

$$
\mathrm{p}_{\mathrm{h}} \mathrm{H}=\mathrm{p}_{\mathrm{md}} \mathrm{M}_{\mathrm{d}}
$$

Equation (10) shows the two effects that stimulate the creation of new technologies.

First is the price effect. The price of the good using the scarce factor will be higher from equation (9). Therefore, there will be more innovation for the skilled factor, which becomes relatively scarce as $M_{d}$ increases to $M_{d}^{\prime}$. Second is the market size effect. This encourages innovation for the more abundant factor, since there would then be a larger number of workers who would use the new machine. This effect would stimulate the creation of more technologies for medium-skilled workers as ICT makes distant workers available.

Given $\mathrm{H} / \mathrm{M}_{\mathrm{d}}$, relative price has to adjust to satisfy equation (11). From equation (9) relative price can change only if $\mathrm{N}_{\mathrm{h}} / \mathrm{N}_{\mathrm{md}}$ changes. Therefore, the relative skill bias of technology has to adjust to clear the technology market. Equation (9) and (11) together give this equilibrium skill bias:

has decreasing returns thus allowing a tractable solution to the firm's problem. There are constant returns at the aggregate sectoral level, as in the endogenous growth literature, following Aghion and Howitt (1992). A depending on the continuum of machines adopted gives aggregate decreasing returns. Decreasing returns to innovation in each sector are also considered, in the modeling of the innovation process. I thank a referee for making these points. He also points out that $\mathrm{H}$ is likely to be more productive than $\mathrm{M}$. But even in this case, the market size effect will dominate if $\mathrm{M}$ is sufficiently larger than $\mathrm{H}$ to compensate for the latter's greater productivity. Suppose there are constant returns to scale in the aggregate for the $H$ sector but decreasing returns in the $M$ sector, so that $Y_{m d}=N_{m d} M_{d}^{\alpha}$, where $\alpha<$ 1. The equilibrium condition (10) then becomes $\mathrm{p}_{\mathrm{h}} \mathrm{H}=\mathrm{p}_{\mathrm{md}} \mathrm{M}_{\mathrm{d}}^{\alpha}$. More technologies will still be created for medium-skilled workers if $\mathrm{M}_{\mathrm{d}}$ is sufficiently large. 


$$
\frac{N_{h}}{N_{m d}}=\frac{A_{h}}{A_{m d}}=\left[\frac{H}{M_{d}}\right]^{\rho /(1-\rho)}
$$

Equation (12) implies that when $\rho>0$, so that the goods are gross substitutes, the market size effect is larger than the price effect, so that $\mathrm{N}_{\mathrm{md}}$ rises with $M_{d}$. Therefore Result 1 follows.

Result 1: If the elasticity of substitution exceeds unity, so that high and medium-skill goods are gross substitutes, a larger relative supply of medium- skilled workers will lead to more medium-skill biased technologies being created in the developed country.

Substituting equation (12) in equation (5) for the skill premium:

$$
\omega_{d}=\frac{p_{h} N_{h}}{p_{m d} N_{m d}}=\left[\frac{H}{M_{d}}\right]^{(2 \rho-1) /(1-\rho)}=\left[\frac{H}{M_{d}}\right]^{\sigma-2}
$$

Thus if $\sigma>2$ the medium-skill biased technical change induced by a rise in $M_{d}$ relative to $\mathrm{H}$ will lead to such a large substitution of $M_{d}$ for $\mathrm{H}$ that the long-run relative demand curve for skills (Figure 2) is upwards sloping. Therefore the final skill premium lies below its initial level.

Since the creation and adoption of new machines takes time, immediately after a rise in $M_{d}$, the skill premium for the relatively scarce factor $\mathrm{H}$ rises along the short-run relative skill demand curve from $\omega_{\mathrm{d}}$ to $\omega_{d}^{\prime}$ (Figure 2). But, over time, endogenous technical change shifts the short-run demand curve inwards, as demand shifts in favor of $M_{d}$ and the long-run skill premium falls to $\omega_{d}^{\prime \prime}$. The movement is from 1 to 2 to 3 in Figure 2, and the long-run relative demand for skills, joining points 1 and 3 slopes upwards $^{9}$. Result 2 follows:

\footnotetext{
${ }^{9}$ If $\sigma<2, \omega_{d}^{\prime \prime}$ would be between $\omega_{d}^{\prime}$ and $\omega_{\mathrm{d}}$ and the long run demand curve would be downward sloping. Technical change would reduce the skill premium but not below its initial value.
} 


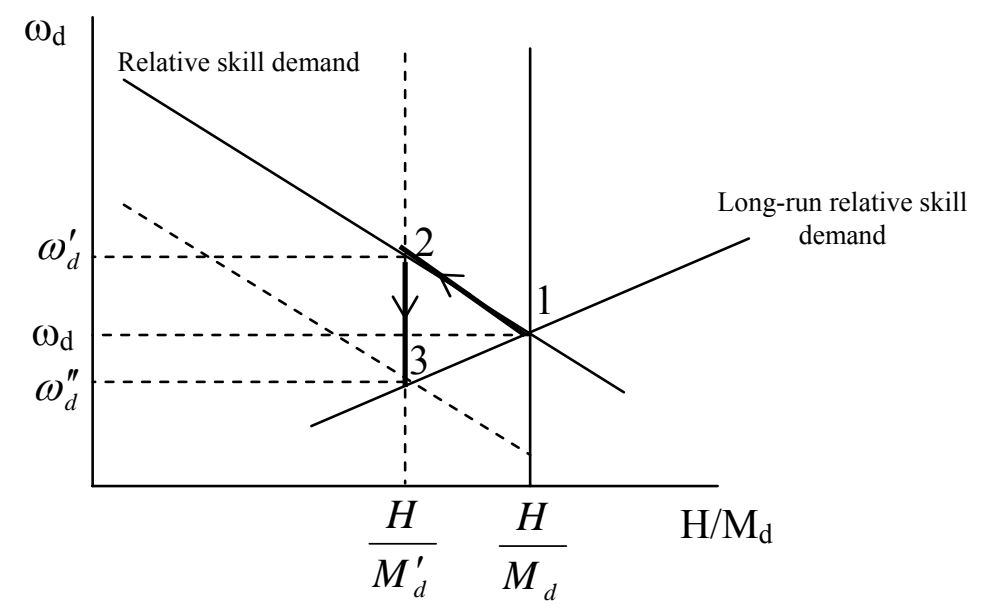

Figure 2: The long-run developed country relative skill demand when $\sigma>2$

Result 2: If the elasticity of substitution exceeds two, a rise in the supply of mediumskilled labour will moderate the skill premium in the developed economy, thus making the domestic wage distribution more equitable.

The net effect will be more equality in the developed economy. As these changes take place in the latter, what happens in the EME, which is the source of the rise in $M$ ? We turn to this in the next section.

\subsection{The emerging market economy}

$M$ and $L$ type of workers dominate in such an economy, so that the aggregate output can be written as:

$$
Y_{e}(t)=\left[\left(A_{l}(t) L(t)\right)^{\rho}+\left(A_{\text {me }}(t) M_{e}(t)\right)^{\rho}\right]^{1 / \rho}
$$

As in the earlier section we interpret this as representing a two good economy, each good produced by one type of worker and aggregated by consumer preferences over the two goods.

$$
\begin{aligned}
& Y_{l}=A_{l} L \\
& Y_{m e}=A_{m e} M_{e} \\
& U_{c e}=\left[Y_{l}^{\rho}+Y_{m e}^{\rho}\right]^{1 / \rho}
\end{aligned}
$$

Initially, we consider the economy to be closed. A characteristic of underdevelopment is the small size of the medium-skill sector. Employment here is demand determined with production of the low skill good serving to absorb medium-skilled labour that is 
not able to find employment in producing $\mathrm{Y}_{\text {me }}$. This makes the elasticity of substitution of relative demand between the two types of labour, $\sigma(\equiv 1 /(1-\rho))$, high. In the development process, the slack of medium-skilled workers doing low-skilled work gets absorbed in higher skill work and more low-skill workers get some skill training. The shrinking of $L$ and expansion of $M$ that occurs with development so that $M$ replaces $L$ requires $\sigma>1$.

Data is of poor quality so that there are few estimates of the elasticity of substitution between different skill types in EMEs. Angrist (1995), using a comprehensive but rare labour force survey, estimates the fall in skill premiums resulting from a sudden rise in the supply of graduates in Palestine in the 1980s; his estimations imply a $\sigma$ of 2. Early cross country estimates gave very high values of $\sigma$ leading to a belief that the labour demand for relative skills was flat. Improvements in estimation techniques reduced the $\sigma$ estimated. When Fallon and Layard (1995) corrected for complementarities between skilled labour and capital in a cross country study their estimated $\sigma$ fell to a range between 0.6-3.5. But capital use, and its complementarity, is likely to be relatively lower in a populous EME, raising $\sigma$. More informal and flexible production techniques would also tend to raise $\sigma$. Therefore we take $\sigma>3$ in the EME compared to $\sigma>2$ in the developed country. It is not an essential assumption. It makes the relative skill demand curve flatter in the EME, with some dampening of the skill premium, but also increases its outward shift, thus raising the skill premium.

The wage for each skill class equals its marginal product:

$$
\begin{aligned}
& w_{L}=\frac{\delta Y_{e}}{\delta L}=A_{l}^{\rho}\left[A_{l}^{\rho}+A_{m e}^{\rho}\left(M_{e} / L\right)^{\rho}\right]^{(1-\rho) / \rho} \\
& w_{M e}=\frac{\delta Y_{e}}{\delta M_{e}}=A_{m e}^{\rho}\left[A_{l}^{\rho}\left(M_{e} / L\right)^{-\rho}+A_{h}\right]^{(1-\rho) / \rho}
\end{aligned}
$$

The two equations imply that $\delta w_{L} \mid \delta\left(M_{e} \mid L\right)>0$ and $\delta w_{M e} \mid \delta\left(M_{e} \mid L\right)<0$ respectively. Thus everything else equal, as the proportion of unskilled workers shrinks, their wages should rise and those of medium-skilled workers should fall. 
The skill premium, or the wage of medium-skilled workers divided by the wage of low-skilled workers, is obtained by combining the two equations (17):

$$
\ln \omega_{e}=\frac{\sigma-1}{\sigma} \ln \left(\frac{A_{m e}}{A_{l}}\right)-\frac{1}{\sigma}\left(\ln \frac{M_{e}}{L}\right)
$$

where $\omega_{e}=w_{M e} \mid w_{L}$. Differentiating (15) with respect to $M_{e} \mid L$ :

$$
\frac{\delta \ln \omega_{e}}{\delta \ln \left(M_{e} \mid L\right)}=-\frac{1}{\sigma}<0
$$

since $\sigma>0$.

For a given skill-bias of technology, if L falls to L', so that medium-skilled workers become relatively abundant, the skill premium falls along the downward sloping demand curve (Figure 3). Equation (18) gives the relative demand curve and equation (19) its slope. Although there are many kinds of rigidities, large reserves of mediumskilled labour absorbed in low-skilled work ${ }^{10}$ imply that $\sigma$ may be higher in the EME compared to the developed economy. In that case, the slope of the curve in Figure 3 would be lower compared to that in Figure (1). The flatter curve reflects the ease with which labour transfers from the low to the medium-skilled sector, so that mediumskilled wages are restrained.

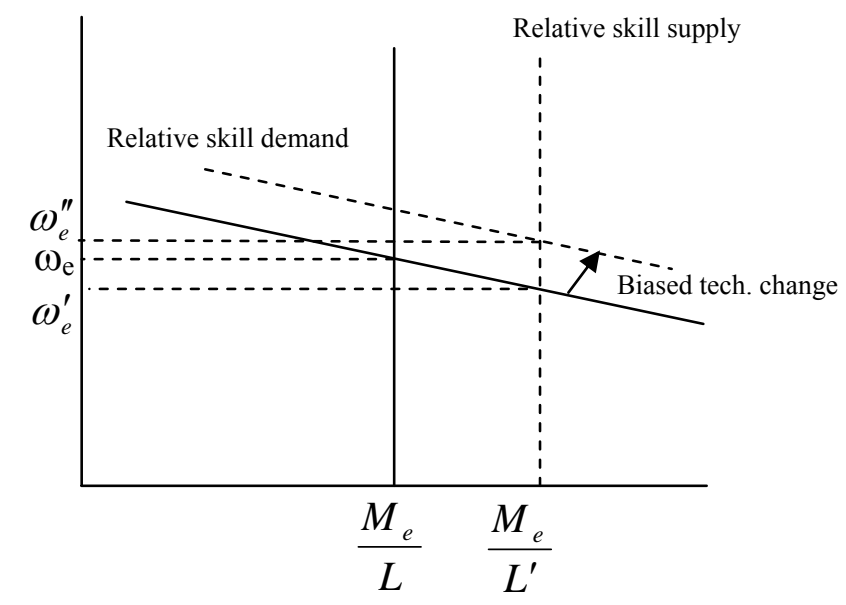

Figure 3: The relative demand for skills and relative wages in the EME

\footnotetext{
${ }^{10}$ In an EME, heterogeneous quality of education can make high-skill labour equivalent to medium-or even low-skilled. The Indian national association of software and service companies (NASSCOM) estimates that only $25 \%$ of technical graduates and $10-15 \%$ of general college graduates are suitable for employment in the offshore IT and BPO industries. But special training programs and certification programs, some of which they are designing, can quickly upgrade them helping the shift of labour from low to medium-skilled (NASSCOM, 2006).
} 
In a closed economy the fall in L may be minor, especially if the economy is stagnating and population birth rates are high. But as some of $M_{e}$ type workers begin to do distance work for firms based abroad, more of the medium-skilled slack doing $\mathrm{L}$-type work is absorbed in M-type jobs. Taking a comparative static snapshot, $\mathrm{L}$ falls to $\mathrm{L}^{\prime}$ and the ratio $\mathrm{M}_{\mathrm{e}} / \mathrm{L}^{\prime}$ rises; the relative supply curve shifts out. The skill premium $\omega_{\mathrm{e}}$ falls to $\omega_{e}^{\prime}$ along the downward sloping demand curve.

But once $A_{m e} / A_{1}$ is allowed to change, the final value of $\omega_{e}$ depends on any changes in the relative skill bias of technology. Differentiating equation (18) with respect to this ratio:

$$
\frac{\delta \ln \omega_{e}}{\delta \ln \left(A_{m e} \mid A_{l}\right)}=\frac{\sigma-1}{\sigma}
$$

Since $\sigma>1$, relative improvements in $\mathrm{A}_{\mathrm{me}}$ raise the skill premium. The relative demand curve shifts outwards, raising the skill premium from $\omega_{e}^{\prime}$ to $\omega_{e}^{\prime \prime}$ in Figure 3. Inequality rises in the EME but the almost flat demand curve and large supply response to a wage rise prevent a large rise in the skill premium. Inequality is moderated by the shrinkage of L, as more labour moves to higher wage and productivity categories. Since $\sigma>1$, advances in technology used with mediumskilled workers raise their relative productivity and wages. That is, such technical change is skill-biased. The tendency of the skill premium to fall with a rise in the relative supply of skills is counteracted by a rise in relative demand for skills due to technical development.

Endogenous technical change will occur also in the EME. We examine this, considering first the closed economy prior to the development of ICT, and then bringing in global sourcing.

\subsubsection{Endogenous technical change in the EME}

The sectoral production functions written as functions of the number of specialized equipment for medium-skilled and low-skilled workers respectively are, $\mathrm{Y}_{\mathrm{me}}=\mathrm{N}_{\mathrm{me}}$ 
$M_{e}$ and $Y_{L}=N_{L}$ L. Competitive pricing as before gives the inverted relative demand for the medium-skill intensive good as:

$$
p_{e}=\frac{p_{m e}}{p_{l}}=\left[\frac{N_{m e} M_{e}}{N_{l} L}\right]^{\rho-1}
$$

Although in a low per capita income EME induced technical progress is slow, it does occur. The marginal increase in profit due to a new machine in each sector is given by the derivative of $p_{m e} Y_{m e}$ and $p_{1} Y_{1}$ respectively by $N_{m e}$ and $N_{1}$ :

$$
p_{m e} M_{e} \text { and } p_{l} L
$$

Creation of new equipment stops when the marginal increase in profits equals the marginal cost of innovation in both sectors. That is, in equilibrium:

$$
\frac{p_{m e} M_{e}}{p_{l} L}=1
$$

This development occurs locally and must satisfy the local equilibrium condition $(23)^{11}$. Before opening out, slow local development process leads to a steady fall in $L$ as labour is slowly absorbed in higher skill $M$ activities. Since this process determines the $\mathrm{M}_{\mathrm{e}} / \mathrm{L}$ ratio, relative price has to adjust to clear equation (23), and from equation (21), the only way relative price can adjust is if induced technical progress changes the $\mathrm{N}_{\mathrm{me}} / \mathrm{N}_{1}$ ratio.

Equations (21) and (23) together give the equilibrium skill bias as:

$$
\frac{N_{m e}}{N_{l}}=\frac{A_{m e}}{A_{l}}=\left(\frac{M_{e}}{L}\right)^{\rho /(1-\rho)}
$$

As $\frac{M_{e}}{L}$ rises with development, as long as $\rho>0$, equation (24) implies that the skillbias of technology will rise. That is, the ratio $\mathrm{N}_{\mathrm{me}} / \mathrm{N}_{1}$ will rise. More equipment will be created for medium-skill workers. Although the price of the medium-skill good is damped by the rise in relative supply of medium-skill workers, their rising numbers implies the market size effect will dominate.

Substituting from equation (24) gives the skill premium in this economy as:

\footnotetext{
${ }^{11}$ There is a large literature suggesting that technology created in developed countries is not "appropriate" for developing countries. Prior to the spread of ICT, technical development in developed countries largely favored high-skilled workers that were more plentiful in such countries (Acemoglu, 2002). And there was hardly anything available for medium-skill workers, adversely affecting induced technical change in EMEs also. Our analysis implies a possible reversal of this tendency.
} 


$$
\omega_{e}=\frac{p_{m e} N_{m e}}{p_{l} N_{l}}=\left[\frac{M_{e}}{L}\right]^{(2 \rho-1) /(1-\rho)}=\left[\frac{M_{e}}{L}\right]^{\sigma-2}
$$

Since $\sigma$ is high in this economy, the skill premium will tend to rise over time. From Figure (5), the long-run relative demand for skills is upward sloping, but almost flat so that the rise in skill premium is moderate.

Result 3: In a closed developing economy, as labour is slowly absorbed in the medium-skill sector, the market size effect dominates the price effect and induced technical change is biased towards medium-skills. Elasticity of substitution is high but the supply response moderates the rise in the skill premium.

Figure 4 shows the dynamic adjustment. The flatter slope of the relative demand curve, combined with a large supply response to a rise in the skill premium implies that the net rise is minor. The skill premium first falls along the downward sloping relative skill demand from $\omega_{\mathrm{e}}$ to $\omega_{e}^{\prime}$ (point 1 to 2 , Figure 4 ) as $L$ shrinks to $L$ ' with development. But the relative demand curve shifts outwards as technology responds to the market size effect so that the skill bias rises. The skill premium rises from $\omega_{e}^{\prime}$ to $\omega_{e}^{\prime \prime}$ (point 2 to 3 on Figure 4). The net effect is a slight rise in the skill premium from $\omega_{\mathrm{e}}$ to $\omega_{e}^{\prime \prime}$ as equation (21) also implies. The long-run relative medium skill demand joining points 1 and 3 has a small positive slope. But the impact will be moderate if the fall in $L$ is slow. Global sourcing can create a large fall in $L$.

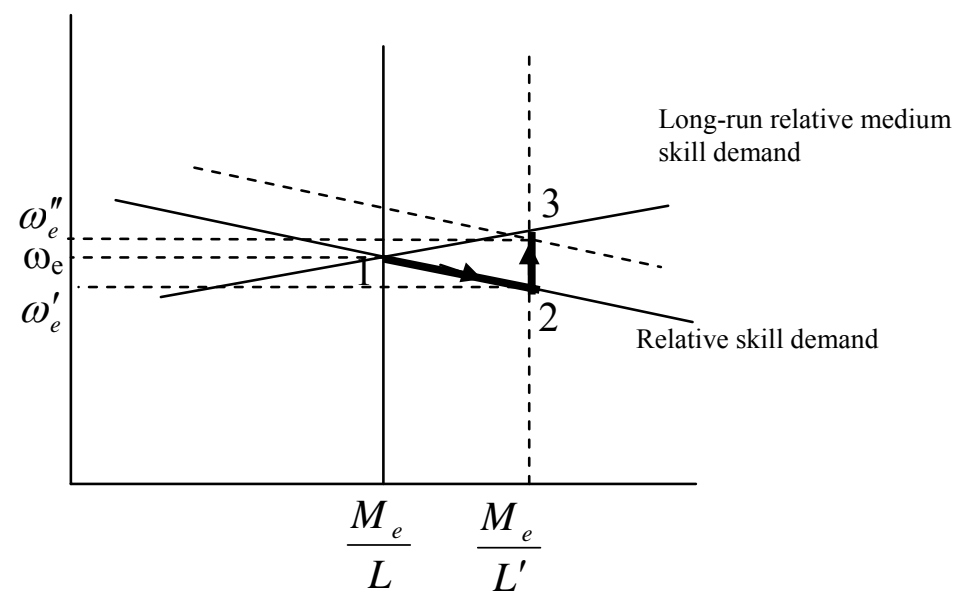

Figure 4: The long-run EME relative skill 


\section{Adding up the effects of global sourcing}

So far we have considered the comparative static effects of a rise in $M_{d}$ in the developed economy and a fall in $L$ in the EME. Since it is global sourcing that causes these changes in relative labour skills, in this section we put together the effect on the two economies and check for consistency in technology adoption and aggregate labour supplies. The market size effect, as $M_{d}$ rises in the developed country and $L$ falls in the EME leads to a rise in $\mathrm{N}_{\mathrm{md}}$ to $N_{m}^{\prime}>N_{m d}$. This technology has to be shared across the two countries for global sourcing to occur, although a major part of the development will occur in the developed country. It follows that $N_{m e}^{\prime}=N_{m d}^{\prime}=N_{m}^{\prime}>N_{m e}$. That is, after global sourcing both countries have new improved technology available for the good produced with medium-skilled labour. We assume trade in goods continues to be restricted, in order to focus on the effect of global sourcing. Therefore $\mathrm{p}_{\mathrm{m}}$ is equalized across the two countries, not because of trade, but because of similar technology being used. The new price $\mathrm{p}_{\mathrm{m}}$ is such that $\mathrm{p}_{\mathrm{m}}<$ $\mathrm{p}_{\mathrm{me}}<\mathrm{p}_{\mathrm{md}}$. The price of the good produced by medium-skilled labour falls below its earlier levels in both countries. Pre-interaction, its price had been relatively higher in the developed country. Better technology, as well as higher supply of medium-skilled labour causes $\mathrm{p}_{\mathrm{m}}$ to fall.

The sectoral production functions now are:

$$
\begin{aligned}
& Y_{h}=A_{h} H \\
& Y_{m d}=A_{m}^{\prime} M_{d}^{\prime} \\
& Y_{m e}=A_{m}^{\prime} M_{e} \\
& Y_{l}=A_{l} L^{\prime}
\end{aligned}
$$

Where $M_{d}^{\prime}>M_{d}$ and L' $<$ L. $M$ available to the developed country exceeds its presourcing level and $L$ in the EME is lower than the pre-sourcing level. Since labour demand is derived from product demands, the skill premium depends on the relative price of skill intensive goods and on the marginal products from (26). The developed country skill premium decreases to $\omega_{d}^{\prime \prime}$ as in Figure 2 and from equation (13), as productivity of medium-skill labour improves.

$$
\omega_{d}^{\prime \prime}=\frac{p_{h}}{p_{m}} \frac{A_{h}}{A_{m}^{\prime}}
$$




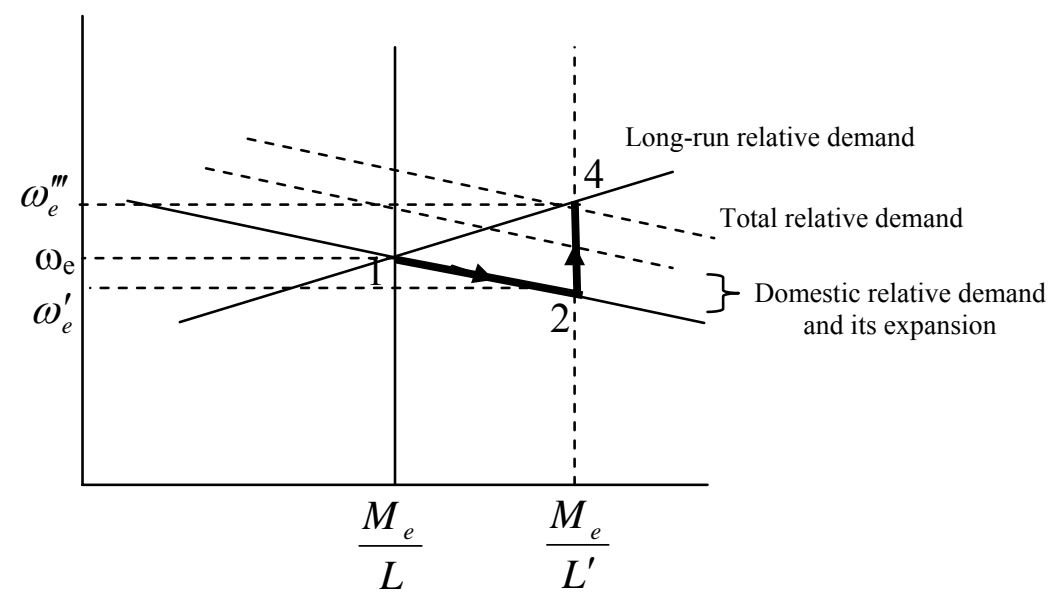

Figure 5: The long-run EME relative skill demand with global sourcing

The rise in $A_{m}^{\prime}$ dominates the fall in $p_{m}$, so that the demand for $M_{d}$ rises even though the price of the good it produces falls. Although the purely domestic changes tend to barely increase the skill premium $\omega_{\mathrm{e}}$ to $\omega_{e}^{\prime \prime}$ in the EME, (Figure 4 and equation 25), the international demand for $M$ will shift out the relative skill demand more and lead to a further rise in demand for $M$, so that the upward slope in the long-run relative skill demand is slightly steeper. The net effect would be a rise in the medium-skill premium to $\omega_{e}^{\prime \prime \prime}$. Adjustment now proceeds through 1, 2 to 4 in Figure 5.

Result 4: Adding the demand for EME medium-skills from the developed country will tend to further raise the skill premium and medium-skill employment in the EME.

Global sourcing implies there is a difference between labour employed in a country and that producing domestic output. In the developed country labour producing domestic output, $M_{d}^{\prime}$ exceeds labour working in the country $M_{d}$ by $M_{d}^{\prime}-M_{d}$. This raises the market size effect and therefore induces more medium-skill biased technical change in the developed country, from equation (11).

$$
M_{d}^{\prime}=M_{d}+\left(M_{d}^{\prime}-M_{d}\right)
$$

Result 5: Global sourcing creates a medium-skill bias in developed country technical progress. 
In the EME while $\mathrm{M}_{\mathrm{e}}$ produces domestic output, medium-skilled workers working in the country $\left(M_{e}^{e}\right)$ exceed $\mathrm{M}_{\mathrm{e}}$ by $M_{d}^{\prime}-M_{d}$. The latter is the number of EME workers now producing output for the developed country.

$$
M_{e}^{e}=M_{e}+\left(M_{d}^{\prime}-M_{d}\right)
$$

Initially the average wage in the EME is:

$$
w=\frac{M_{e} w_{M e}+L w_{L}}{M_{e}+L}
$$

The new average wage is:

$$
w^{\prime}=\frac{M_{e} w_{M e}^{\prime}+\left(M_{d}^{\prime}-M_{d}\right) w_{M e}^{\prime}+L^{\prime} w_{L}}{M_{e}+\left(M_{d}^{\prime}-M_{d}\right)+L^{\prime}}
$$

Since $M_{d}^{\prime}>M_{d}, L^{\prime}<L, w_{M e}>w_{L}$, and $w_{M e}^{\prime}>w_{M e}$ it follows that $w^{\prime}>w$, leading to Result 6:

Result 6: The average wage in the EME rises after global sourcing.

From aggregate labour market clearing we must have:

$$
M_{e}+L=M_{e}+\left(M_{d}^{\prime}-M_{d}\right)+L^{\prime}
$$

Given relative labour supply, and relative labour demand derived from consumer demand, the wage premium is determined. But after a shock to relative labour supply, equilibrium in the creation of new machines across the two sectors requires relative prices to adjust (from equations 11 and 23). The latter requires adjustment in relative $\mathrm{N}$, further changing relative labour demand and the skill premium. The increase in medium-skilled workers available induces development of $\mathrm{N}_{\mathrm{m}}$ from the developed country technology market clearing equation (11), and the fall in L induces development and adoption of $\mathrm{N}_{\mathrm{m}}$ from the EME technology market clearing equation (24).

If domestic technology firms equip M-workers employed to produce domestic output, while foreign technology firms equip distant labour, and the improved technology $A_{m}$ is able to meet increased demand for $\mathrm{Y}_{\text {me }}$ without a change in domestic employment in this sector, $M_{e}$, so that the fall in $\mathrm{L}$ is equal to the rise in $M_{d}$, and the elasticities of substitution are similar, the two equations continue to hold with $\mathrm{A}_{\mathrm{m}}$ and $\mathrm{N}_{\mathrm{m}}$ equated across the two countries, and equilibrating adjustments in $\mathrm{N}_{\mathrm{m}}$. If the elasticity of 
substitution is higher in the EME, technology market clearing will also require a fall in $\mathrm{N}_{1}$, as is clear from equation (32) obtained by substituting $\mathrm{N}_{\mathrm{m}}$ from equation (11) in equation (24).

$$
\frac{N_{h}}{N_{l}}=\frac{A_{h}}{A_{l}}=\left(\frac{M_{e}}{L^{\prime}}\right)^{\sigma-1}\left(\frac{H}{M_{d}^{\prime}}\right)^{\sigma-1}
$$

Turning to dynamic adjustments, $M_{e}$ may also rise as domestic demand for mediumskill goods rises and labour supply responds to rising domestic skill premiums, thus contributing further to a speedier transition. The process would continue as long as there is slack in $L$ to be absorbed, ensuring a faster absorption of the slack.

Result 7: The rise in demand for $M$ will induce a faster catch-up in the EME.

The catch-up will slow down as the period of training required for labour in the $L$ sector to make the transition to medium-skill work lengthens. Meanwhile, more $M$ type labour in the EME will be acquiring $H$ type skills, so that it begins to resemble the mature economy. When transition is complete technology development will respond again to the rise in $H$ availability and a new developed economy dynamics will set in.

The rapid development of the Indian information technology and information technology enabled services sectors supports the analytical results derived above. Underemployment of skills, or the size of $\mathrm{L}$, fell as the total direct employment in this sector grew by over a million from 284,000 in $1999-2000$ to a projected $1,287,000$ in 2005-06. Direct employment was growing at above 50 percent per annum during this period. Indirect and induced employment created another 3 million jobs. Thus distant work enabled a large rise in medium-skilled employment. Skill premiums rose with wage inflation averaging 10-15 per cent annually. Yet Indian offshore operations continued to provide cost savings of 40-50 per cent because of declines in telecom and other overhead costs, productivity gains and economies of scale (NASSCOM, 2006). Thus substantial induced technical advances improved the productivity of this labour. Companies found that redesigning business processes to exploit automation in offshoring back-office functions releases large new revenues above the obvious labor cost savings - this is the induced technical change we model. 
There is other evidence that improvements in technology are favouring mediumskills. ICT based technologies are not naturally high-skill complementary. The rapid expansion in menu driven and applied software programs makes it possible for users to undertake complex operations they do not really understand. Just as the technology developed and stabilized a car driver did not need to know the engine, increasing the market for cars. Similarly computers can now be used even without knowledge of programming - these developments enhance medium-skills. For example Microsoft's mission is, given the basic technology, to continuously develop applications to expand the user base. In India, software is being developed to make it possible for outsourcing to go to the villages and draw upon rural labour.

Evidence is beginning to collect regarding changes in the effect of outsourcing on wage premiums. Feenstra and Hanson (1995) argued that offshoring of capital and production to Mexico from the US in the eighties raised the wages of skilled workers in both countries. Skilled US workers benefited from cheaper imports but relative wages and employment of unskilled workers fell. Since technology continued to favor skilled workers, in this period, firms employed relatively fewer low-skilled workers. They were cheap but less productive. According to our analysis, as global sourcing continues, technology should begin to favor medium-skilled workers, putting downward pressure on skill premiums in developed countries, and raising them in EMEs. More recent research provides some support for this thesis. Egger and Pfaffermayr (2004) demonstrate that equalization has occurred both within and between the EU-15 member countries, but not within some Eastern European countries. Farrell et. al. (2005) expect some rise in wages in low income country. For example, they estimate the wages of engineers in India will rise to Brazilian levels which are about thirty percent of US levels for equivalent skill categories. Global inequality has fallen due to the trade-linked rise in growth and employment in the populous countries of East Asia, China and India.

\section{Policy implications and concluding remarks}

New technologies combined with the importance of induced technological progress have important implications for policy. The traditional argument is that technological development increases inequality and in order to reduce the latter policy should build 
in various kinds of restraints on technology and restrictions on labour markets. But our analysis implies that it is precisely when labour markets are flexible, and maximum inducements exist for the development of technology, that the impact of technological development increases equality, in both developed countries and EMEs. Therefore policy should ensure these conditions in both sets of countries.

Special funds and training programs can be created to moderate short-term adjustment costs for labour in developed countries. An insurance or welfare fund, to upskill and redeploy workers whose jobs migrate abroad, can be established through a low tax on the large transient profits firms make. Policy supported rigidities in EMEs, such as labour laws that make retrenchment difficult, often lower the elasticity of substitution between different labour-skill types. If $1<\sigma<2$, inequality can rise in the EME with development. Therefore these rigidities need to be removed. Policy intervention should be focused on improving facilities for education and training, health and infrastructure. This will facilitate the transition of labour from low to medium-skill categories. Cost of trade fragmentation, or splitting of the production chain across countries, will fall as the fixed cost of new technology equipment is spread leading to its wider adoption (Jones and Kierzkowski, 2005). This is beneficial for equality as well as development, so trade barriers should be removed.

ICT increases the global supply of medium labour skills. Therefore more technical change that uses these skills may be induced. This will tend to moderate the dominant trend of the last 30 years where technical change favored high-skills. The standard understanding is that labour scarcity induces capital-intensive technical advances that raise labour productivity. But since there is more learning-by-doing with a large employed labour force even greater productivity improvements, favouring the largest skill category, can occur.

The consequence of high-skill bias in technology was that wage dispersion and inequality rose in developed countries, and the technology available was not appropriate for factor endowments in EMEs. The rise in demand for medium-skills due to technical change may reverse the short-term developed country job losses from global sourcing. Since the technology developed may be more appropriate for 
populous EMEs and will raise demand for their labour, it will allow a faster catch-up. Although skill premiums will tend to rise in the EMEs, equality may rise as the proportion of population employed in the unskilled sector shrinks. Inequality across countries may also fall as the average wage rises in the EMEs.

These sharp results follow from a simple analytic framework with three types of labour skills and assumptions on their distribution across the two country types. The results are therefore strictly valid only in that framework. But insofar as the framework captures dominant features, it isolates current tendencies. The predictions need to be rigorously tested as data on the effects of recent technical developments begins to accumulate.

\section{References}

Acemoglu, D., 2002. Technical Change, Inequality, and the Labour Market. Journal of Economic Literature, XL, 7-72.

Acemoglu, D., 1998. Why do New Technologies Complement Skills? Directed Technical Change and Wage Inequality. The Quarterly Journal of Economics, 113, 4, 1055-1089.

Acemoglu, D., 1997. Training and Innovation in an Imperfect Labour Market. Review of Economic Studies, 64, 445-464.

Aghion, P. and P. Howitt, 1992. A Model of Growth through Creative Destruction. Econometrica. LX, 323-351.

Angrist, J.D., 1995. The Economic Returns to Schooling in the West Bank and Gaza Strip. The American Economic Review, 85, 5, 1065-1087.

Bronfenbrenner, K. \& Luce, S., 2004. The Changing Nature of Corporate Global Restructuring: The Impact of Production Shifts on Jobs in the U.S., China, and Around the Globe. Prepared for the US-China Economic and Security Review Commission, available at http://www.uscc.gov/researchpapers/comm_research_archive.htm.

Diamond, J., 1997. Guns, Germs, and Steel: The Fates of Human Societies, New York: W.W. Norton and Co.

Dossani, R. \& Kenney, M., 2003. Went for Cost, Stayed for Quality?: Moving the Back Office to India? Berkeley Roundtable on the International Economy, Working Paper 156, available at http://repositories.cdlib.org/cgi/viewcontent.cgi?article=1020\&context=brie 
Egger, P. \& Pfaffermayr, M., 2004. Two Dimensions of Convergence: National and International Wage Adjustment Effects of Cross-Border Outsourcing in Europe. Review of International Economics, 12 (5), 833-843.

Fallon, P.R. and P.R.G. Layard, 1975, Capital-Skill Complementarity, Income Distribution, and Output Accounting. The Journal of Political Economy, 83, 2, 279302.

Farrell, D., M. A. Laboissière, J. Rosenfeld, 2005. Sizing the emerging global labour market. The McKinsey Quarterly, 3

Feenstra R.C. \& Hanson, G. H., 1995. Foreign Investment, Outsourcing and Relative Wages, NBER working paper 5121.

Freeman, R., 1986. Demand for Education. Handbook of Labour Economics, Vol. I, O. Ashenfelter and R. Layard, eds. North Holland: Elsevier.

Global Insight, 2004. The Impact of Offshore IT and Services Outsourcing on the US Economy and IT Industry. Sponsored by the Information Technology Association of America, available at http://www.itaa.org/eweb/upload/execsum\%20final.pdf.

Goyal, A., 2006. Global Sourcing: East-West Divide or Synthesis? in Outsourcing \& Offshoring in the 21st Century: A socio economic perspective. H. S. Kehal and V. P. Singh (eds.), Hershey, P.A.: Idea Group Inc...

Habbakuk, H. 1962. American and British Technology in the Nineteenth Century. Cambridge University Press: London.

Hayami, Y., 1998. Toward an East Asian Model of Economic Development. In Y. Hayami and M. Aoki (eds.) The Institutional Foundation of East Asian Economic Development. IEA Conference volume No. 127. 3-35. New York: Macmillan.

Jones R. W. \& Kierzkowski, H., 2005. International Trade and Agglomeration: An Alternative Framework. Journal of Economics, Supplement 10, 1-16.

McKinsey Global Institute. 2003. Offshoring: Is it a Win-Win Game? San Francisco.

NASSCOM(National Association of Software and Service Companies), 2006. Factsheets available at http://www.nasscom.in/Nasscom/templates/NormalPage.aspx?id=2374

Rajghatta, C., 2004. US Makes a Mountain out of a BPO Molehill. Times of India, Mumbai Edition, January 18.

Schmookler. J., 1966. Invention and Economic Growth. Harvard University Press: MA. 